\title{
Proceeding
}

8th INSHS International Christmas Sport Scientific Conference, 5-7 December 2013. International Network of Sport and Health

Science. Szombathely, Hungary

\section{Selected characteristics of gait in women of different ages}

\author{
JAN DOŠLA , DUŠAN HUPKA, RADEK MUSIL \\ Faculty of Sport Studies, Masaryk University. Brno, Czech Republic
}

\begin{abstract}
Došla, J., Hupka, D. \& Musil, R. (2014). Selected characteristics of gait in women of different ages. J. Hum. Sport Exerc., 9(Proc1), pp.S538-S545. In our research we have attempted to find out and compare force and time characteristics of gait in women. We measured and compare women in two age groups - 18-30 (group 1) a 46-60 (group 2). The average height of both groups was same, $167 \mathrm{~cm}$, while the average weight and average body mass index were different (group 1 - weight $62 \mathrm{~kg}$, BMl 22,3, group 2 - weight 68 kg, BMI 24,6). For measuring, pressure shoe insoles were used (Pedar Mobile, Novel Munich, 99 sensors, $100 \mathrm{~Hz}$ ). Each person had three attempts: two trial attempts, the third one was measured. For observation, we selected three stances of each leg, always between the third and eighth stride. We measured force characteristics F1, F2, F3 and time characteristics t, t1, t2, t3. Significant differences between both groups were found in $\mathrm{t} 3$ on the left leg (time between peak force in active part of stance and peak force in passive part of stance). With applied force (F1, F2, F3) during stance, after recalculating per a kilogram of weight, no statistically significant differences were found. Key words: GAIT, PEDAR, FORCE, BODY MASS INDEX, ACTIVE PART OF STANCE, PASSIVE PART OF STANCE.
\end{abstract}

Corresponding author. Faculty of Sport Studies, Masaryk University. Brno, Czech Republic.

E-mail: dosla@fsps.muni.cz

8th INSHS International Christmas Sport Scientific Conference, 5-7 December 2013. International Network of Sport and Health Science. Szombathely, Hungary.

JOURNAL OF HUMAN SPORT \& EXERCISE ISSN 1988-5202

(c) Faculty of Education. University of Alicante

doi:10.14198/jhse.2014.9.Proc1.44 


\section{INTRODUCTION}

Walking may be considered the most important physical activity. It is suitable for virtually every individual and its effect on the cardiovascular system is unquestionable. It is therefore important to identify and describe the correct gait mechanisms.

Homo erectus, whose pelvis and femurs enabled him to overcome long distances by walking, may be considered fully bipedal. Besides its benefits, upright walking, however, began to cause a number of health problems such as pain in the lower back, herniated discs, arthritis in the hip and knee joints and leg framework collapse (Vařeka \& Vařeková, 2009). The importance of physical activity such as walking is nevertheless considerable. According to Frömel (2005) daytime walking amounts to 50 to 80 minutes, which ranks it among the most frequently reported physical activities. In contrast, Berkey (2003) reports only 24 minutes of this activity per day in the USA, which may already be assessed as insufficient. Older people in particular appreciate the importance of walking, i.e. a physical activity which is simultaneously capable of maintaining optimal function of the body (Wert \& VanSwearingen, 2009). A number of changes were demonstrated when comparing different age groups, where the older people tended to display walking speed reduction, smaller extension in the hip joint (Hageman, 1986; Ostrosky \& VanSwearingen, 1994; Winter, 1990) as well as diminished step length and changes in the step width (Ostrosky \& VanSwearingen, 1994; Winter et al., 1990; McGibbon, 2003; Brach et al., 2008).

A proper gait technique may affect the proper posture which according to Wert \& VanSwearingen (2009) is a problem mainly among the elderly. Older people may also demonstrate more problems with gait variability, which indicates impaired mobility (Brach et al., 2008). Basic locomotor pattern of adult gait is developed around the 7th year of age, although some gait parameters become stabilized as late as 16 to 18 years of age (Pasparakis \& Daras, 2009).

According to Pasparakis \& Daras (2009) the gait cycle may be divided into two phases: a stance and a swing. In our work the stance phase was investigated where one foot remains in contact with the pad. This phase accounts for $62 \%$ of the gait cycle, while the swing forms the remaining 38\% (Ayyappa, 1997; Huges \& Jacobs, 1979). The stance phase may be divided into three basic parts: introductory double-limb position, single-limb position and the final double-limb position. During the ordinary walk at a natural rate, the ratio of these phases is approximately 10: 40:10 percent of the total gait cycle time. Changes in the speed or frequency of the movement result in the alteration of this ratio. The speed increase is usually accompanied by the increase in the proportion of single-limb phase and the decrease in the proportion of both double-limb phases (Kirtley, 2006; Perry \& Burnfield, 2010). With age the share of double-limb phase lengthens while the swing phase shortens (Hagemann, 1986). In terms of the movement of the lower limbs and the center of gravity movement, the stance phase may further be divided into five successive phases, namely initial contact (IC), loading response (LR), midstance (MST), terminal stance (TST) and preswing (PS) (Pasparakis \& Daras, 2009; Ayyappa, 1997).

According to various authors, adulthood may be divided into four periods: 18-30, 30-45, 46-60 and 60 years of age and older. In our research we deal with the quality of gait of the general population in two age periods, i.e. $18-30$ and $46-60$ years of age. 


\section{MATERIAL AND METHODS}

In our research we have attempted to identify and compare force and temporal characteristics of gait in women. Women in two age groups: $18-30$ (Group 1) and 46-60 years of age (Group 2) were measured and compared. The number of persons measured in Group 1 was 31 while in Group 2, 20 subjects were measured. The average height in both groups was the same $167 \mathrm{~cm}$, while the average weight and average Body Mass Index were different (Group 1 - weight $62 \mathrm{~kg}$, BMI 22.3, Group 2 - weight $68 \mathrm{~kg}$, BMI 24.6). None of the studied women displayed any medical problems that could affect their gait technique.

Table 1. The research groups

\begin{tabular}{cccccccc}
\hline sex & age group & height & height & weight & weight & BMI & BMI \\
& & Mean & Std.Err. & Mean & Std.Err. & Mean & Std.Err. \\
\hline woman & $18-30$ & 167,3 & 1,15 & 62,31 & 2,19 & 22,25 & 0,63 \\
woman & $46-60$ & 166,8 & 1,53 & 68,48 & 2,91 & 24,60 & 0,83 \\
\hline
\end{tabular}

Each subject was tested in civilian clothing and footwear which was the same for all research participants. Uniform shoes with flat soles without pads and patterns on the outsole were used to ensure standard and objective conditions for all measurements participants as well as the reliability and validity of the research results. Following preparation within which subjects were familiarized with measuring devices, research venue and the measurement procedure itself, parts of the research equipment were attached on the subject's body while the subjects also put on uniform footwear with capacitive insoles. To evaluate the load, the mask was applied to the entire surface of the pressure insole.

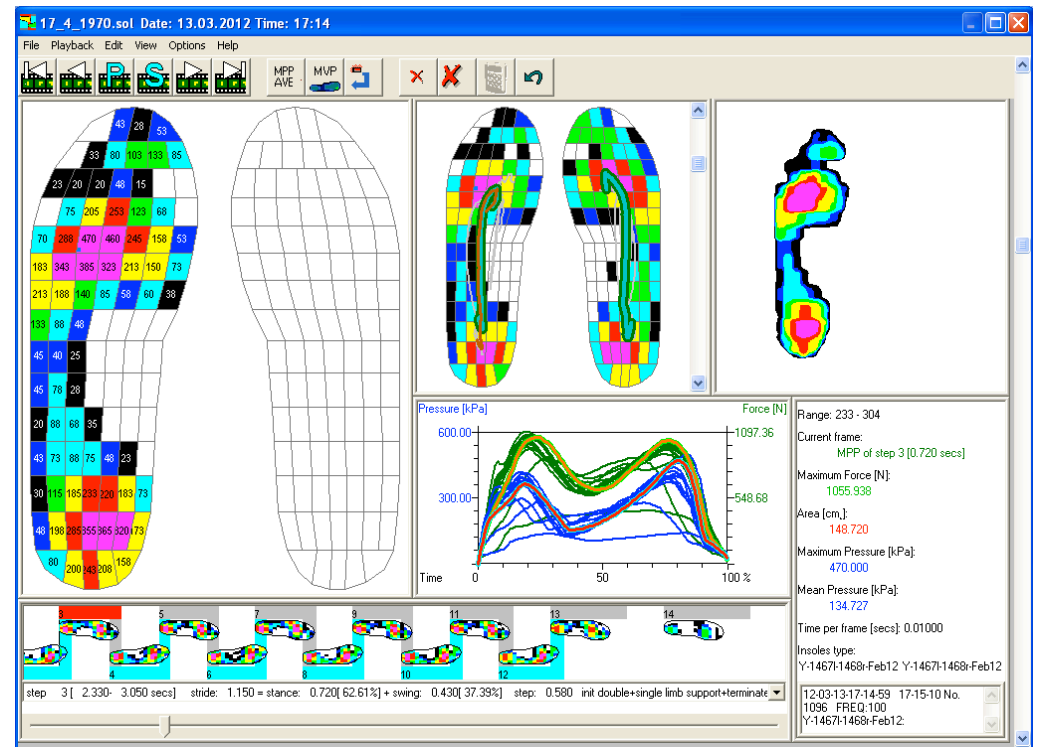

Figure 1. Step analysis of the third step with maximal forces (Pedar)

Measurements were conducted using pressure shoe insoles (Pedar Mobile, Novel Munich, 99 sensors, 100 $\mathrm{Hz}$ ) where each person was given three attempts, i.e.two trial attempts and the final one which was measured. The recorded data included the entire stretch of the walk, i.e. to 17 consecutive steps. Three stances of each leg, always between the fifth and tenth steps were chosen for observation. These steps 
were selected following the stabilization of the typical walk of each tested person after the fifth step in the given attempt (Perry \& Burnfield, 2010; Kirtley, 2006). The following parameters were compared: F1 maximum vertical ground reaction force during absorption stage (loading response, LR), F2 - the lowest force during decline between both peaks, F3 - maximum vertical ground reaction force during propulsive stage (terminal stance, TST). In addition, four temporal characteristics were measured: $t$ - complete stance time, $\mathrm{t} 1$ - absorption stage time, $\mathrm{t} 2$ - propulsive stage time and $\mathrm{t} 3$ - time between F1 and F3.

For statistics, we used analysis of variance (ANOVA) and Fisher's post hoc LSD test. The level of $5 \%$ was set as a limit for statistically significant differences $(p=0.05)$.

\section{RESULTS}

The comparison of the force parameters failed to show statistically significant differences between the compared groups. The statistical significance was compared following the conversion to the kilogram of weight. Women in Group 1 displayed a relative force of 10.74 at the maximum F1 values and at F3 the values were of 11.73 and 11.27 for the left and right foot respectively. At the maximum $\mathrm{F} 1$ values the women in Group 2 demonstrated a relative force at the maximum F1 values of 10.52 and 10.3 for the left and right foot respectively and at F3 the values were of 11.31 and 11.09 for the left and right foot respectively.

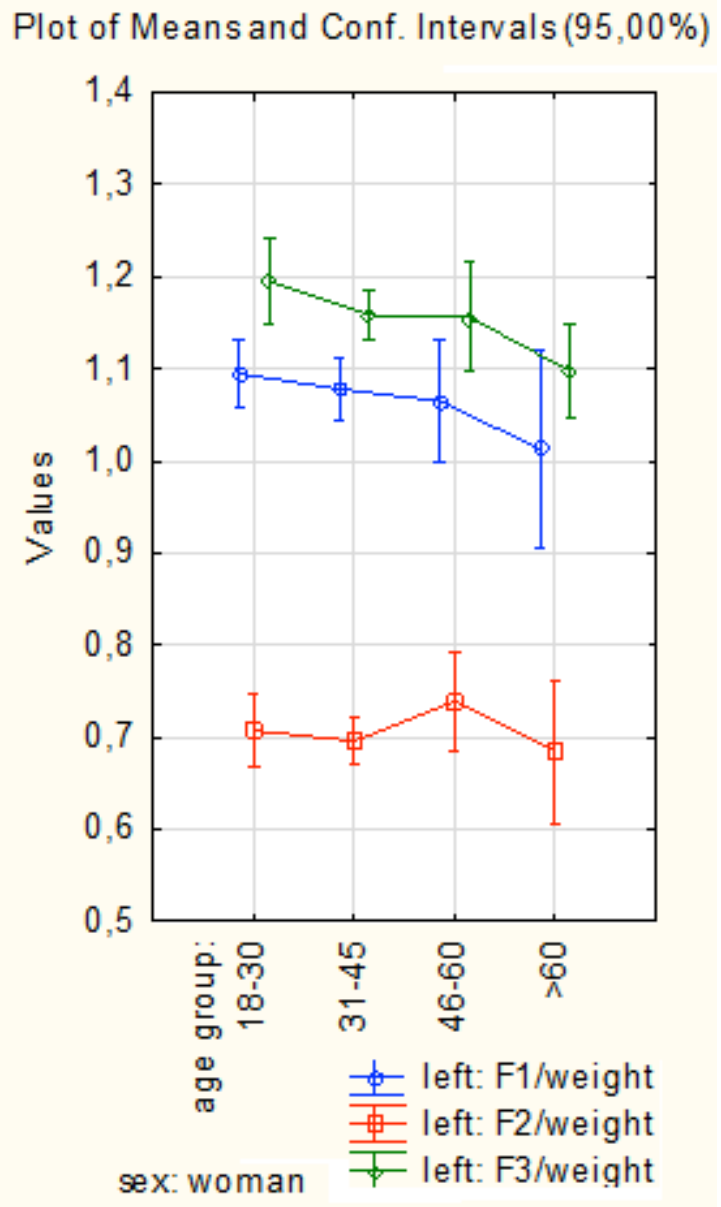

Figure 2. Relative force during stance on the left foot 
The relative force at the lowest load during stance: in the first group the F2 values recorded were of 6.94 and 6.88 for the left and right foot respectively, in the second group the analogical values were those of 7.22 and 7.2 .

The absolute F1 force recorded in Group 1 was $668 \mathrm{~N}$ on the left foot and $666 \mathrm{~N}$ on the right foot, while in Group 2 the respective values were those of $716 \mathrm{~N}$ and $700 \mathrm{~N}$. The absolute F3 force recorded in the first group was $729 \mathrm{~N}$ on the left foot and $703 \mathrm{~N}$ on the right foot. With the second group the respective values were those of $771 \mathrm{~N}$ and $758 \mathrm{~N}$. The boundary between midstance (MST) and terminal stance (TST): F2 recorded in absolute terms stood at $432 \mathrm{~N}$ for the left foot and $428 \mathrm{~N}$ for the right foot in Group 1, while the second group demonstrated an indentical value of $492 \mathrm{~N}$ for both feet.

The highest force values in both groups were achieved at the end stage of terminal stance at the F3 value where slightly higher values were achieved on the left foot. Younger women were able to achieve a higher relative F1 and F3 force values in comparison with older women. With the F2 values, however, the results were exactly opposite.

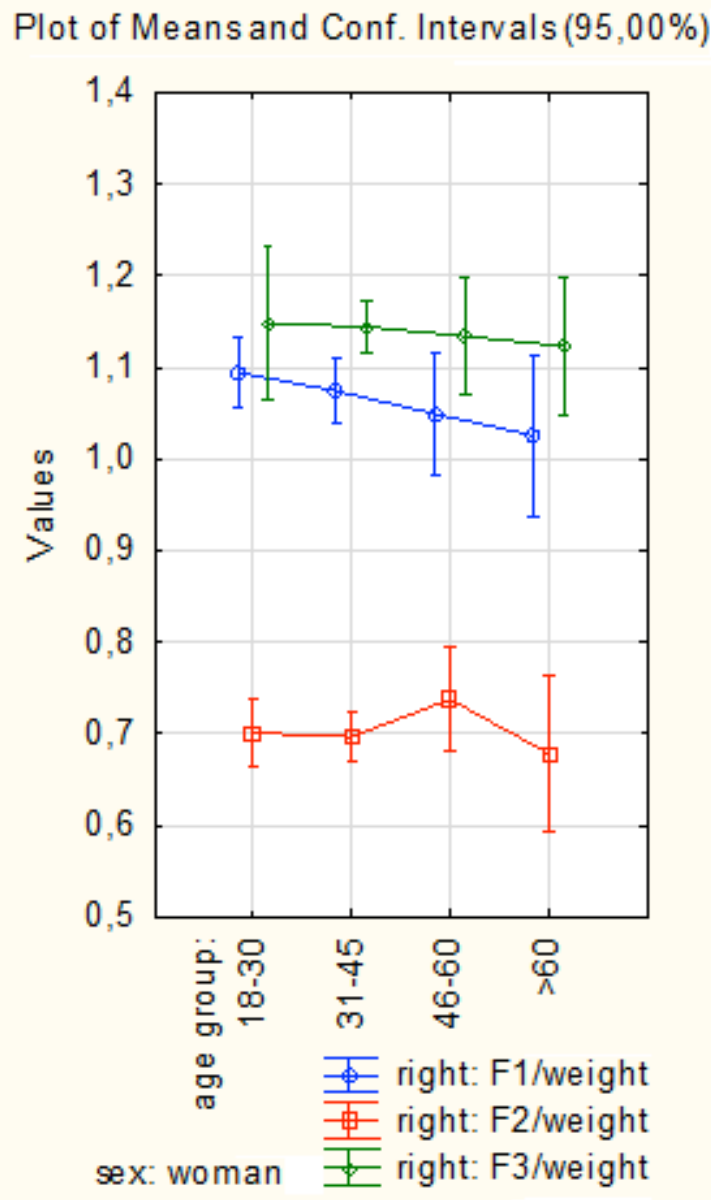

Figure 3. Relative force during stance on the right foot

Concerning temporal characteristics, statistically significant differences were found in the $\mathrm{t} 3$ parameter of the left foot $(p=0.02)$ while the right foot also displayed a certain difference $(p=0.1)$. Other temporal 
characteristics failed to yield any statistically significant differences. Women in Group 1 demonstrated a longer stance. This difference mainly occurred in the first part of the stance - $\mathrm{t} 1$ (loading response and midstance), while the duration of the second part of stance - $t 2$ (terminal stance and preswing) was virtually the same. The duration of the stance in women in the first group was $0.64 \mathrm{~s}$ on the left foot and $0.65 \mathrm{~s}$ on the right foot while the second group generated the same value of $0.63 \mathrm{~s}$ for both feet. Group 1 demonstrated the $\mathrm{t} 1$ duration of $0.31 \mathrm{~s}$ on the left foot and $0.32 \mathrm{~s}$ on the right foot while Group 2 again generated the identical value of $0.3 \mathrm{~s}$ for both feet. The 2 value in the first group was $0.34 \mathrm{~s}$ on the left foot and $0.33 \mathrm{~s}$ on the right foot while the second group showed the same result of $0.33 \mathrm{~s}$ for both feet. With the $\mathrm{t} 3$ value the both groups showed identical values for both feet, i.e. $0.36 \mathrm{~s}$ and $0.34 \mathrm{~s}$ respectively. These results indicate a longer duration of the second phase with both the groups.

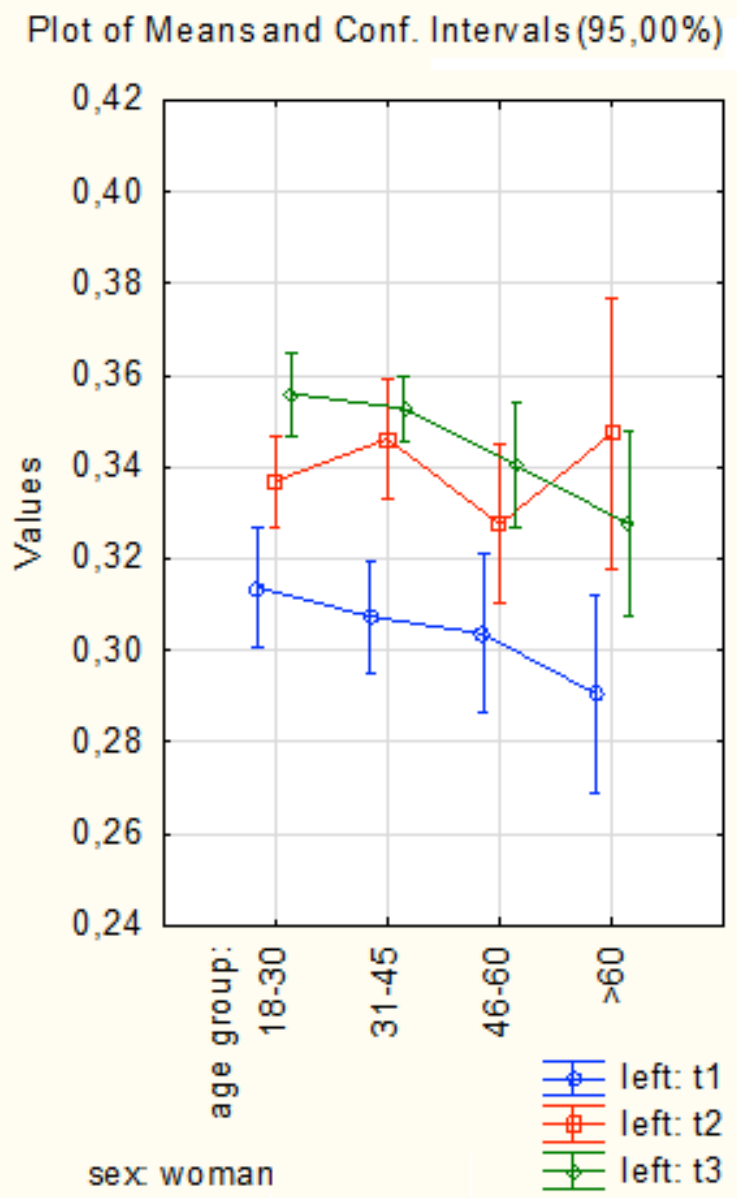

Figure 4. Time characteristics on the left foot

\section{DISCUSSION}

The comparison of the descriptive characteristics of both age groups shows virtually no differences in the body height. In contrast, the weight comparison shows higher values for older women. The comparison of the Body Mass Index in both groups reveals a significantly higher value for older women $(p=0.02)$. 
The only statistically significant finding generated through the comparison of the two groups was the t3 parameter, i.e. the duration of time between F1 and F3, which was substantially shorter in older women. Although the other results were not statistically confirmed, we are able to observe some interesting changes and trends here. Concerning the F, F1, F2 and F3 parameters, the significant findings mainly included the differences between the left and right feet, which showed that the force exerted on the left foot was higher in both age categories. We may assume that this is due to the use of the left foot in take-off. In comparison of absolute force indicators, the older women tended to achieve higher values due to the greater weight. Younger women, on the other hand, showed higher relative F1 and F3 indicators, meaning they were able to act with more force, both in the active and passive part of a stance. In contrast, younger women tended to attain lower F2 values than older women, both in the absolute and relative terms, following the conversion to a kilogram of weight.

When examining the temporal characteristics, a longer duration of a stance in younger women was observed. The $t 1$ phase was also longer in younger women, while the t2 phase showed no differences between both age groups. If we had made a cross comparison between $\mathrm{t} 1$ and $\mathrm{t} 2$, the $\mathrm{t} 2$ phase would have been longer for both age groups.

\section{CONCLUSIONS}

Although it may be concluded that except for the $\mathrm{t} 3$ duration, the examination of the subjects did not bring any statistically significant differences, we may still say that some of the differing values especially in the force parameters may indicate changes that occur during aging. In particular these include the changes of the maximum F1 and F3 forces, which may decrease with age.

\section{REFERENCES}

1. Ayyappa E. (1997). Normal Human Locomotion, Part 1: Basic Concepts and Terminology. Journal of Prosthetics and Orthotics, 9(1), pp.10.

2. Berkey, C.S. et al. (2003). One-year changes in activity and inactivity among 10 to 15 year old bioys and girls: Relationship to change in Mody Mass Index. Pediatr, 111, pp.592-600.

3. Brach, J., Studenski, S., Perera, S., Vanswearingen, J.M. \& Newman, A.B. (2008). Stance Time and Step Width Variability Have Unique Contributing Impairments in Older Persons. Gait and Posture, 27(3), pp.431-439.

4. Frömel, K. (2005). Pohybová aktivita v životě člověka. Závěrečná zpráva o řešení výzkumného zámèru MSM155100015. Olomouc, FTK UP, 68 p.

5. Hageman, P.A. \& Blanke, D.J. (1986). Comparison of gait of young women and elderly women. Phys Ther, pp.1382-1387.

6. Hughes, J. \& Jacobs, N. (1979). Normal human locomotion. Prosthetics and Orthotics International. 3, pp.4-12.

7. Kirtley, C.H. (2006). Clinical gait analysis. Theory and practise. Elsevier Limited: Philadelphia.

8. McGibbon, C.A. (2003). Toward a better understanding of gait changes with age and disablement: neuromuscular adaptation. Exerc Sport Sci, 31, pp.102-108.

9. Ostrosky, K.M., VanSwearingen, J.M., Burdett, R.G. \& Gee, Z.A. (1994). Comparison of gait characteristics in young and old subjects. Phys Ther, 74, pp.637-644; discuss. pp.644-646.

10. Pasparakis, D. \& Daras, N. (2009). Normal walking Principles, basic concepts, terminology 3dimensional clinical gait analysis. EEXOT, 60(4), pp.183-194. 
11. Perry, J. \& Burnfield, J.M. (2010). Gait analysis; normal and pathological function. Thorofare NJ: Slack.

12. Wert, D.M., Brach, J., Perera, S. \& Vanswearingen, J.M. (2010). Gait Biomechanics, Spatial and Temporal Characteristics, and the Energy Cost of Walking in Older Adults With Impaired Mobility. Physical Therapy, 90(7), pp.977-985.

13. Wert, D.M., Brach, J., \& Vanswearingen, J.M. (2009). Energy cost of walking contributes to physical fiction in older adults. In: American Geriatrics Society Annual Conference. 2009 Annual Scientific Meeting Abstract Book, 57(4). Chicago, IL: Wiley-Blackwell.

14. Vařeka, I. \& Vařeková, R. (2009). Kineziologie nohy. 1. vyd. Olomouc: Univerzita Palackého v Olomouci.

15. Winter, D.A., Patla, A.E., Frank, J.S. \& Walt, S.E. (1990). Biomechanical walking pattern changes in the fit and healthy elderly. Phys Ther, 70, pp.340-347. 